\title{
Lead induced increase of blood pressure in female lead workers
}

\author{
K Nomiyama, H Nomiyama, S-J Liu, Y-X Tao, T Nomiyama, K Omae
}

Occup Environ Med 2002;59:734-739

See end of article for authors' affiliations

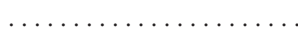

Correspondence to:

Dr K Nomiyama, Midori

3-12-1,

Minamikawachi-Machi,

Tochigi-Ken 329-0433,

Japan;

nomiyama@jichi.ac.jp

Accepted 10 April 2002

\begin{abstract}
Aims: Although lead exposure has, in the absence of mathematical modelling, been believed to elevate blood pressure in females, it is necessary to clarify the relation between lead and blood pressure by eliminating confounding factors in the analysis.

Methods: Blood lead was measured in 193 female workers, including 123 lead exposed workers. Possible confounding factors were controlled by multiple regression analyses.

Results and Conclusion: Blood lead above $40 \mu \mathrm{g} / \mathrm{dl}$ was found to be the most potent factor for elevating systolic/diastolic blood pressure. Aging, urine protein, and plasma triglyceride also contributed to systolic/diastolic/pulse pressure increase, but hypertensive heredity did not. Data suggested that lead induced changes in lipoprotein metabolism may play an important role in the lead induced blood pressure increase in female workers.
\end{abstract}

B ood pressure is believed to become increased among residents exposed to lead, such as that emitted from house paint, gasoline, and other sources. Several reports are available concerning the lead-blood pressure relation in which confounding factors (age, sex, hypertensive heredity, nutrition, lead exposure level, etc) were adjusted by mathematical modelling. ${ }^{1-7}$ Harlan and colleagues ${ }^{8}$ described a close association between blood lead and systolic or diastolic blood pressure, based on the Second National Health and Nutrition Examination Survey data (NHANES II). We have also applied mathematical modelling to our survey data on 220 male workers, and found that diastolic blood pressure was increased in male workers with blood lead concentrations above $40 \mu \mathrm{g} / \mathrm{dl} .^{9}$ On the other hand, Harlan ${ }^{10}$ indicated that blood lead was closely related to systolic and diastolic pressures in males but not in females, based on multiple regression analysis. Female workers were normally not included or exposed to lower concentrations of lead, and no consensus for the relation between lead exposure and blood lead has been established.

We therefore examined the lead induced increase of blood pressure in female workers by the use of mathematical modelling.

\section{METHODS \\ Study population}

The study population consisted of 127 female crystal toy making workers (age range 17-44 years, mean (SD) 27.3 (5.4) years; duration of employment $0.8-25.0$ years, mean 7.2 (4.6) years) and 70 female sewing workers (age range $16-58$ years, mean 24.2 (6.4) years; duration of employment $0.1-11.4$ years, mean $2.2(2.2)$ years). All female workers were examined in each factory. Both factories were located in Beijing City, China. The working environment of the crystal toy making factory was contaminated with lead dust at concentrations of $0.39-1.91 \mathrm{mg} / \mathrm{m}^{3}$ (mean $0.92(0.42)$ ) that were much higher than the occupational exposure limit of $0.05 \mathrm{mg} / \mathrm{m}^{3}$ recommended by the American Conference of Governmental Industrial Hygienists. ${ }^{11}$ The suburban environment, the target site, was also seriously polluted with lead from automobile exhaust gases, although no precise data were available for the target site at the time of our survey. Table 1 presents the results of the biological indices of lead in workers.

\section{Parameters and methods}

We recorded details of the age, hypertensive heredity, working plants, and duration of employment of the target population. Blood and urine were also collected. One trained medical doctor then determined blood pressure (systolic and diastolic) by sphygmomanometer (mercurial manometer) after 15 minutes or more rest in an adjacent room. Pulse pressure was calculated as the difference between systolic and diastolic blood pressures. Blood lead, haemoglobin, plasma total cholesterol, triglyceride, high density lipoprotein, creatinine, urea nitrogen, calcium, phosphorus, $\delta$-aminolevulinic acid, and alkaline phosphatase, and urine protein, glucose, amino acids, calcium, phosphorus, and $\delta$-aminolevulinic acid were analysed. Renal tubular reabsorption of phosphorus was calculated. Plasma low density lipoprotein was estimated, based on Freewald's formulae. The ratio of plasma urea nitrogen to creatinine was calculated.

Blood lead was determined as follows: whole blood was diluted 10 times with ultrapurified water. Diluted blood $(0.9$ $\mathrm{ml}$ ) was mixed with $0.1 \mathrm{ml}$ concentrated nitric acid (ultrapure grade) and then incubated for deproteinisation in a hot water bath of $70^{\circ} \mathrm{C}$ for five minutes. In a diluted specimen of the supernatant of the deproteinised blood, lead concentration was measured by flameless atomic absorption spectrophotometry (Hitachi Z-9000) with the Zeeman effect background correction. Daily internal quality control checks were performed.

$\delta$-Aminolaevulinic acid (ALA) concentrations in plasma and urine was determined by the method of Oishi and colleagues. ${ }^{12}$ Haemoglobin was determined by the cyanmethaemoglobin method. Total cholesterol, triglyceride, and high density lipoprotein were determined by an automatic biochemical analyser, Abbott VP, using the Cholesterol-FA Test (Wako), Triglyceride G-FA Test (Wako), and HDL FA Test (Wako), respectively. Plasma low density lipoprotein was estimated based on Freewald's formulae. Plasma creatinine, phosphorus, urea nitrogen, uric acid, glucose, cholesterol, and triglyceride were determined with an Abbott VP using reagent Folin-Wu, ${ }^{14}$ Phospha-B Test (Wako), a-gent BUN (Dainabot),

Abbreviations: ALA, $\delta$-aminolaevulinic acid; FEIP, fractional excretion of phosphorus; HDL, high density lipoprotein; LDL, low density lipoprotein PC, partial correlation 
Table 1 Biological exposure indices in workers

\begin{tabular}{|c|c|c|c|c|c|c|}
\hline & \multicolumn{3}{|c|}{ Lead exposed workers $(n=123)$} & \multicolumn{3}{|c|}{ Referent workers $(n=70)$} \\
\hline & Mean & (SD) & Range & Mean & (SD) & Range \\
\hline Blood lead ( $\mu \mathrm{g} / \mathrm{dl})$ & 55.42 & 13.52 & $22.5-99.4$ & 6.42 & 1.55 & $3.8-11.4$ \\
\hline$\delta$-ALA in plasma ( $\mu \mathrm{g} / \mathrm{I})$ & 80.36 & 72.90 & $3.31-380.83$ & 2.35 & 0.82 & $1.34-5.88$ \\
\hline$\delta$-ALA in urine $(\mathrm{mg} / \mathrm{I})$ & 16.41 & 13.50 & $1.25-63.38$ & 1.08 & 0.21 & $0.66-1.55$ \\
\hline
\end{tabular}

\begin{tabular}{|c|c|c|c|c|}
\hline Determinants & Parameter estimate & $\mathrm{R}^{2}$ & Partial correlation & $p$ value \\
\hline \multicolumn{5}{|l|}{ Systolic blood pressure } \\
\hline Blood lead & 0.1260 & 0.0938 & 0.2651 & 0.0003 \\
\hline Age & 0.4763 & 0.0908 & 0.2359 & 0.0014 \\
\hline Urine protein & 0.0417 & 0.0768 & 0.2125 & 0.0041 \\
\hline Plasma triglyceride & 0.0501 & 0.0549 & 0.2068 & 0.0052 \\
\hline \multicolumn{5}{|l|}{ Diastolic blood pressure } \\
\hline Blood lead & 0.1045 & 0.1174 & 0.3481 & 0.0001 \\
\hline Plasma triglyceride & 0.0305 & 0.0645 & 0.2088 & 0.0061 \\
\hline Age & 0.2215 & 0.0665 & 0.1852 & 0.0153 \\
\hline Urine protein & 0.0200 & 0.0359 & 0.1746 & 0.0224 \\
\hline Plasma low density lipoprotein & 0.0452 & 0.0021 & 0.1627 & 0.0335 \\
\hline Hypertension heredity & -1.1989 & 0.0025 & -0.1205 & 0.1165 \\
\hline \multicolumn{5}{|l|}{ Pulse pressure } \\
\hline Urine protein & 0.0246 & 0.0481 & 0.1965 & 0.0080 \\
\hline Age & 0.2516 & 0.0722 & 0.1934 & 0.0091 \\
\hline Plasma triglyceride & 0.0217 & 0.0419 & 0.1413 & 0.0578 \\
\hline Blood lead & 0.0414 & 0.0375 & 0.1406 & 0.0590 \\
\hline FEIP & 0.1097 & 0.0187 & 0.1069 & 0.1522 \\
\hline
\end{tabular}

Factors shown whose $p$ values were less than 0.2 .

a-gent Uric Acid (Dainabot), Glucose FA-Test (Wako), Cholesterol-FA Test (Wako), and Triglyceride G-FA Test (Wako), respectively. Plasma sodium and potassium were analysed by flame photometry, and chloride by the chloridemeter.

Urine protein and glucose were determined with an automatic biochemical analyser, Abbott VP, using Tonein TP (Otsuka) and the Glucose FA-test (Wako). Urine amino acids and creatinine were estimated by the trinitrobenzene sulphonic acid method ${ }^{13}$ and Folin-Wu method, ${ }^{14}$ with the use of Abbott VP. Urine phosphorus, alanine aminotransferase, and alkaline phosphatase were assessed with an automatic biochemical analyser, Abbott VP, employing Phospha-B Test (Wako), GPT-FA Test (Wako), and Alkaline Phospha-FA Test (Wako) to detect lead induced lesions of the kidneys. ${ }^{15}$

In order to avoid observation bias, all subjects and examiners were unaware of our concern about the relation between blood lead and blood pressure: all workers and doctors who measured blood pressure and familial heredity, and who took blood and urine samples, and the technician who measured biological parameters. Subjects were questioned on their familial hypertensive heredity in their routine health check interviews before being informed of the aim of this study, in order to diminish differential recall bias.

\section{Statistical analysis}

Twenty two parameters related to blood pressure were subjected to factor analysis for classifying into 10 factors. The parameters were age and duration of employment, hypertensive heredity (number of persons suffering from hypertensive disease), blood lead, plasma triglyceride, plasma cholesterol, plasma high density lipoprotein (HDL), plasma low density lipoprotein (LDL) (calculated after Freewald's formulae), haemoglobin, plasma $\delta$-aminolaevulinic acid (ALA), urine
ALA, urine protein, urine glucose, urine amino acids, plasma creatinine, plasma urea nitrogen, ratio of plasma urea nitrogen to creatinine, fractional excretion of phosphorus (FEIP), plasma phosphorus, plasma calcium, urine calcium, and plasma alkaline phosphatase. Multiple forward regression analyses were employed for 10 representative parameters selected by factor analysis to evaluate the possible confounders, and multiple regression and the Pearson correlation procedure were used for evaluating the significance of the selected confounders. Multiple logistic regression analyses were employed for evaluating dose-effect and dose-response relations between blood lead and blood pressures after controlling for possible confounders. Some of the data, including blood lead concentrations, were missing because of insufficient sample volume for analyses. However, this is not related to the exposure or health status of workers. All analyses were performed using SAS 6.12 statistical software (SAS Institute, Cary, NC, USA).

\section{RESULTS}

\section{Possible confounders for blood pressure}

From the 22 parameters, 10 representative parameters were chosen by factor analysis, one each from the above 10 factors, as follows: blood lead, age, hypertensive heredity, plasma cholesterol, plasma triglyceride, plasma low density lipoprotein, plasma urea nitrogen, urine protein, urine amino acids, and fractional excretion of phosphorus. The above parameters were then subjected to multiple forward regression analysis with a level of entry of 0.2 . As table 2 shows, these parameters were applied to multiple regression analysis; the potent parameters modulating blood pressure were as follows: ( 1 ) for systolic blood pressure: blood lead, age, urine protein, and plasma triglyceride; (2) for diastolic blood pressure: blood 


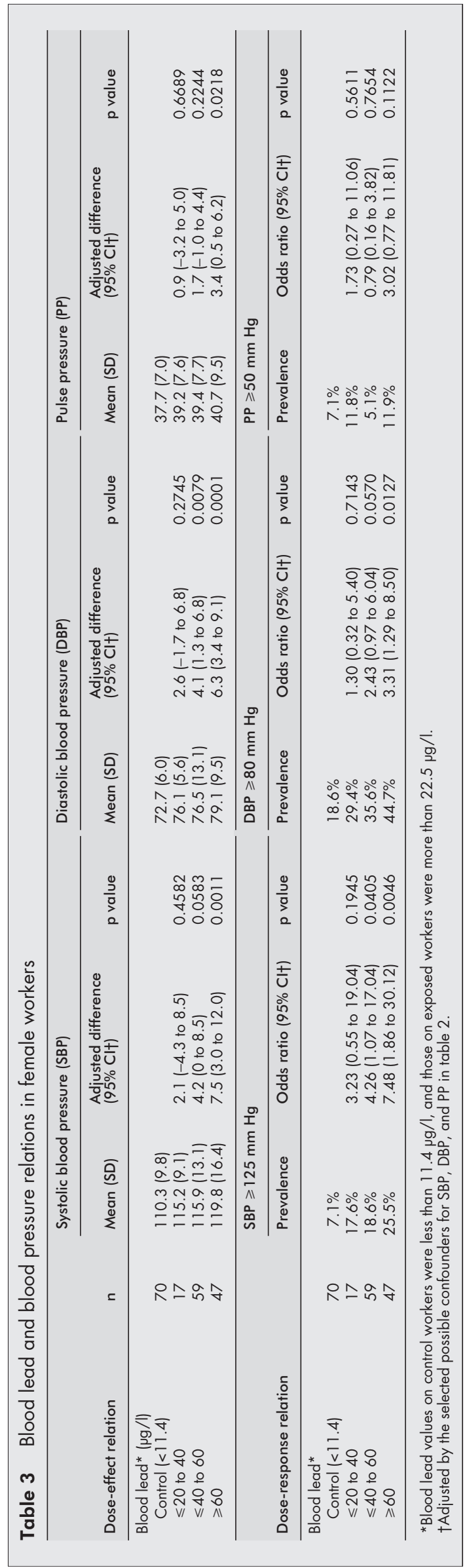

lead, plasma triglyceride, age, urine protein, and plasma low density lipoprotein; and (3) for pulse pressure: urine protein, age, plasma triglyceride, and blood lead.

Relations between blood lead and blood pressure Contribution of blood lead to blood pressure (table 2) Blood lead was selected by multiple forward regression analyses on blood pressures. $\mathrm{R}^{2}$ values for blood lead were higher than the other selected parameters in systolic and diastolic blood pressures.

\section{Dose-effect relation between blood lead and blood} pressure (table 3)

The systolic blood pressure in the two groups with blood lead concentrations of $40-60 \mu \mathrm{g} / \mathrm{dl}$ and $\geqslant 60 \mu \mathrm{g} / \mathrm{dl}$ was higher than that of the control group (blood lead $<11.4 \mu \mathrm{g} / \mathrm{dl}$ ), by 4.2 and $7.5 \mathrm{~mm} \mathrm{Hg}$, respectively. The diastolic blood pressure yielded similar findings: it was significantly higher in the blood lead $40-59 \mu \mathrm{g} / \mathrm{dl}$ and $\geqslant 60 \mu \mathrm{g} / \mathrm{dl}$ groups compared to the blood lead $<20 \mu \mathrm{g} / \mathrm{dl}$ group, by 4.1 and $6.3 \mathrm{~mm} \mathrm{Hg}$, respectively. The pulse pressure of the blood lead $\geqslant 60 \mu \mathrm{g} / \mathrm{dl}$ group was also significantly higher than that of the control group.

Dose-response relation between blood lead and blood pressure (table 3)

The prevalence of an increased systolic blood pressure above $125 \mathrm{~mm} \mathrm{Hg}$ was significantly increased in groups with blood lead concentrations $\geqslant 40 \mu \mathrm{g} / \mathrm{dl}$. The prevalence of an increased diastolic blood pressure above $80 \mathrm{~mm} \mathrm{Hg}$ was also considerably higher in the group with blood lead concentrations $\geqslant 60$ $\mu \mathrm{g} / \mathrm{dl}$ compared to the control group. Nevertheless, the prevalence of an increased pulse pressure (above $50 \mathrm{~mm} \mathrm{Hg}$ ) remained at the same level independent of the blood lead.

\section{Relations between other confounders and blood} pressure (table 2)

Partial correlation between age and blood pressure

Systolic blood pressure increased in significant correlation to age. This was also true for diastolic blood pressure and pulse pressure.

Partial correlation between plasma triglyceride and blood pressure

Significant and close partial correlations were observed between plasma triglyceride and systolic/diastolic and pulse blood pressures.

Partial correlation between urine protein and blood pressure

Urine protein was found to be significantly correlated to blood pressure.

\section{DISCUSSION}

\section{Lead exposure and blood pressure increases}

Lead exposure has been reported by many scientists to increase blood pressure. However, only some epidemiological studies examined the dose-effect or dose-response relations between urine/blood lead and blood pressure: blood pressure was found to be increased in workers with blood lead concentrations of $7 \mu \mathrm{g} / \mathrm{dl}$ on average, ${ }^{16}$ in lead intoxicated patients with blood lead concentrations of $28 \mu \mathrm{g} / \mathrm{dl}$ on average, but not statistically significantly, ${ }^{17}$ and in men with blood lead concentrations of $37 \mu \mathrm{g} / \mathrm{dl}$ on an average ${ }^{18}$ and $6.9 \mu \mathrm{g} / \mathrm{dl}$ on average ${ }^{19}$ Diastolic blood pressure was found to be increased in Canadian citizens with blood lead concentrations of 10.0 $\mu \mathrm{g} / \mathrm{dl}$ or more. ${ }^{20}$ On the other hand, many reports have suggested that lead exposure did not increase blood pressure..$^{21-26}$

It seems quite natural that there should be a disparity among the results, because most authors did not analyse their 
data by the use of mathematical modelling in order to eliminate confounding factors that elevate blood pressure. In addition, although several authors did apply mathematical modeling, ${ }^{1-7}$ the blood lead might be relatively low. On the other hand, the occupational exposures to lead in some Asian and African countries are still higher than those in western countries. ${ }^{57-29}$ We therefore carried out an epidemiological survey on male lead workers, and found that lead exposure was the most potent factor in the diastolic blood pressure increase, and that diastolic blood pressure in the male workers with blood lead concentrations above $40 \mu \mathrm{g} / \mathrm{dl}$ was increased, after mathematical modelling. Other potent factors in raising blood pressure were hypertensive heredity and age. ${ }^{9}$

We carried out the present survey on lead induced increase of blood pressure in female workers, as it has been suggested by Harlan ${ }^{10}$ that lead exposure did not raise blood pressure levels in females residents, and $\mathrm{Wu}$ and colleagues ${ }^{23}$ recently confirmed that lead exposure did not appear to raise blood pressure in female workers. Contrary to the works of Harlan ${ }^{10}$ and $\mathrm{Wu}$ and colleagues, ${ }^{23}$ however, our data yielded the following facts: (1) the potent factors increasing the systolic and diastolic blood pressures calculated by a combination of factor analysis and multiple forward regression analysis were blood lead, age, plasma triglyceride, and urine protein, and did not include hypertensive heredity in common (table 2); and (2) the systolic and diastolic blood pressures were increased in female workers with blood lead concentrations of 40-60 $\mathrm{gg} / \mathrm{dl}$ or higher, as shown by dose-effect and dose-response relation data (table 3).

$\mathrm{Wu}$ and colleagues ${ }^{23}$ reported a lack of evidence of lead induced increase of blood pressure in female workers, probably as a result of the short exposure (0.5-17 years, mean 3.1 (3.2) years). Indeed, it is true that their observed blood lead concentrations $(\mathrm{n}=110,45(18) \mu \mathrm{g} / \mathrm{dl})$ were lower than ours (55 (14) $\mu \mathrm{g} / \mathrm{dl}$ ), and the exposure period of our female workers (0.8-25 years, 7.2 (4.6) years) was longer than theirs (0.5-17 years, 3.1 (3.2) years). Nevertheless, the duration of lead exposure was not selected by multiple forward regression analyses. These findings imply that the exposure period did not contribute much to the lead induced increase of blood pressure.

\section{Other factors increasing blood pressure}

Age also contributed to systolic, diastolic, and pulse pressures (table 2). Systolic and diastolic pressures were significantly increased in female workers above 30 years old (data not shown), as was observed in male workers. ${ }^{9}$

Lilis and colleagues ${ }^{24}$ and Wedeen ${ }^{25}$ suggested that lead induced renal dysfunction might lead to a blood pressure increase in workers. In the present survey on female workers, however, while blood lead was significantly associated with urine amino acids or plasma creatinine $(p=0.0079$, $p=0.0191)$, these parameters were not selected as possible confounders by multiple forward regression analyses. Urine protein was significantly associated with systolic/diastolic/ pulse blood pressures (table 2), but partial correlations (PCs) indicated no associations between blood lead and urine protein on blood pressure (systolic blood pressure: $\mathrm{PC}=-0.0928, \quad \mathrm{p}=0.2142 ; \quad$ diastolic blood pressure: $\mathrm{PC}=-0.0989, \mathrm{p}=0.1982$; pulse pressure: $\mathrm{PC}=-0.0614$, $\mathrm{p}=0.4118$ ). Furthermore, as was shown in table 2, no parameters indicating renal function other than urine protein were selected by multiple forward regression analyses. It is difficult to conclude therefore that the observed blood pressure increase was related to lead induced renal dysfunction, such as glomerular or tubular dysfunction.

However, plasma triglyceride was significantly and closely associated with systolic and diastolic blood pressures and pulse pressure, respectively, even though no significant partial correlation was found between blood lead and plasma triglyceride on systolic/diastolic/pulse blood pressure. Although low density cholesterol was significantly associated with diastolic blood pressure, the partial correlation between low density cholesterol and blood lead was negatively significant ( $\mathrm{PC}=-0.2661, \mathrm{p}=0.0004)$. All the above confounding results may suggest that lead induced changes of lipoprotein metabolism could induce an increase of blood pressure, but the mechanism is not fully elucidated. Kuz'minskaya ${ }^{26}$ reported that potent atherosclerosis occurred in pigeons given cholesterol $600 \mathrm{mg} / \mathrm{day}$ and lead $25 \mathrm{mg} / \mathrm{kg}$ simultaneously over a period of 3.5 months, compared to the pigeons of the control, cholesterol, and lead groups. Sroczynski and colleagues $^{30}$ gave lead acetate to rats intravenously at a dose of $20 \mathrm{mg} \mathrm{Pb} / \mathrm{kg}$ every other day for three months, and found increased concentrations of plasma cholesterol and lipoprotein $\mathrm{T}$ fraction. Sroczynski and colleagues ${ }^{31}$ noted cholesterol digitonin deposits in the inner, median, and outer layers of the aorta in rats administered lead acetate at a dose of $20 \mathrm{mg}$ $\mathrm{Pb} / \mathrm{kg}$ every other day. Revis and colleagues ${ }^{32}$ reported that the plasma high density lipoprotein was increased in pigeons given food containing lead chloride at a dose level of $0.8 \mathrm{mg} / \mathrm{kg}$ over a period of six months. Tarugi and colleagues ${ }^{33}$ observed greatly increased concentrations of plasma cholesterol ester in rabbits given food containing $0.5 \%$ lead acetate over a period of 45 days. Their findings appear to provide support for our proposal concerning the mechanism of lead induced increase of blood pressure, whereby lead induced changes in lipoprotein metabolism may play an important role in the lead induced blood pressure increase in female workers.

\section{Limitations of the study}

In view of the nature of the cross sectional study, there are some limitations of this study. The temporal causality has not been established, and past exposure to lead was hard to be estimated. Furthermore, we cannot exclude the possibility of unexpected factors that were not evaluated and can confound the effect of lead exposure.

\section{Conclusion}

A possible explanation of the results of the study is that lead induced changes in lipoprotein metabolism may play an important role in the lead induced blood pressure increase in female workers, especially at concentrations higher than 40 $\mu \mathrm{g} / \mathrm{dl}$.

\section{ACKNOWLEDGEMENTS}

The authors are grateful to Prof. Koichi Nakamura of Jichi Medical School for his advice in revising the manuscript from the viewpoint of the epidemiologist. The present study was supported by the International Lead Zinc Research Organization, Inc. (ULH-389 to K Nomiyama), Research Triangle Park, NC.

\section{Authors' affiliations}

K Nomiyama, H Nomiyama, Department of Occupational and Environmental Health, Jichi Medical School, Tochigi-Ken 329-0498, Japan

S-J Liu, Beijing Medical University School of Public Health, Beijing 100083, China

Y-X Tao, Beijing City Institute for Occupational Health, Beijing 100020, China

T Nomiyama, Division of Environmental Medicine, Department of Preventive Medicine, Shinshu University School of Medicine, Matsumoto, Nagano 390-8621, Japan

K Omae, Department of Preventive Medicine and Public Health, School of Medicine, Keio University, Tokyo 160-8582, Japan

\section{REFERENCES}

1 World Health Organization. Environmental health criteria. 3: Lead. Geneva: World Health Organization, 1977

2 Restek-Samarzija N, Momcilovic B. Delayed effects of lead on the kidney-factor analysis. Arh Hig Rada Toksikol 1993;44:9-20.

3 Staessen J. Low-level lead exposure, renal function and blood pressure. Verh K Acad Geneeskd Belg 1995;57:527-74. 
4 Navah U, Froom P, Kristal-Boneh E, et al. Relationship of blood lead levels to blood pressure in battery workers. Arch Environ Health 1996;51:324-8

5 Ehrlich R, Robins T, Jordaan E, et al. Lead absorption and renal dysfunction in a South African battery factory. Occup Environ Med 1998:55:453-60.

6 Nordberg $M$, Winblad B, Fratiglioni L, et al. Lead concentrations in elderly urban people related to blood pressure and mental performance: results from a population-based study. Am J Ind Med 2000;38:290-4.

7 Cheng Y, Schwartz J, Sparrow D, et al. Bone lead and blood lead levels in relation to baseline blood pressure and the prospective development of hypertension. The normative aging study. Am J Epidemiol 2001;153:164-71.

8 Harlan WR, Landis JR, Schmouder RL, et al. Blood and blood pressure relationship in the adolescent and adult US population. JAMA 1985:253:530-4.

9 Nomiyama K, Nomiyama H, Liu Y. Elevated blood pressure in lead-refinery workers: dose-effect, dose-response relationships. J Occup Health 1995; 37:s550.

10 Harlan WR. The relationship between blood lead levels to blood pressure in the U.S. population. Environ Health Perspect 1988;78:9-14.

11 American Conference of Governmental Industrial Hygienists. Threshold limit values for chemical substances and physical agents and biological exposure indices. ACGIH, Cincinnati, Ohio, 1997.

12 Oishi H, Nomiyama H, Nomiyama K, et al. Comparison between males and females with respect to the porphyrin metabolic disorders found in workers occupationally exposed to lead. Int Arch Environ Occup Health 1996;68:298-304

13 Nomiyama K. Early detection of chronic cadmium poisoning. Jpn Med J 1973;2587:132

14 Bonsnes RW, Taussky HH. On the colorimetric determination of creatinine by Jaffe reaction. J Biol Chem 1945;158:581-91.

15 World Health Organization. Principles and methods for the assessment of nephrotoxicity associated with exposure to chemicals. Geneva: World Health Organization, 1991:178-9.

16 Fukaya Y, Ohno Y, Matsumoto T, et al. Blood lead and blood pressure-an analysis of health examination materials in two companies for lead poisoning. Jpn J Hyg 1987;42:754-61

17 Dally S, Danan M, Buisine A, et al. Increase of blood lead in alcoholism: relation with blood pressure. Presse Med 1986;15:1227-9.
18 Pocock SJ, Shaper AG, Ashby D, et al. Blood lead concentration, blood pressure, and renal function. Br Med J Clin Res Ed 1984;289:872-4.

19 Rabinowitz $M$, Bellinger D, Leviton A, et al. Pregnancy hypertension, blood pressure during labor, and blood lead levels. Hypertension 1987; 10:447-51.

20 Neri LC, Hewitt D Orser B. Blood lead and blood pressure: analysis of cross-sectional and longitudinal data from Canada. Environ Health Perspect 1988;78:123-6.

21 Britten RH, Thompson A. A health study on ten thousand male industria workers, statistical analysis of surveys in ten industries. Public Health Bulletin 1926:162:1-170.

22 Belknap EL. Clinical studies on lead absorption in humans: blood pressure observations. J Ind Hyg Toxicol 1936;18:380-90.

23 Wu TN, Shen CY, Ko KN, et al. Occupational lead exposure and blood pressure. Int J Epidemiol 1996;25:791-6.

24 Lilis R, Valciukas JA, Kon S, et al. Assessment of lead health hazards in a body shop of an automobile assembly plant. Am J Ind Med 1982;3:33-51.

25 Wedeen RP. Bone lead, hypertension, and lead nephropathy. Environ Health Perspect 1988;78:57-60.

26 Kuz'minskaya GN. Effect of lead poisoning on experimental atherosclerosis. Arkjiv Pathologii 1964;26:833-5.

27 Ho SF, Sam CT, Embi GB. Lead exposure in the lead-acid storage battery manufacturing and PVC compounding industries. Occup Med 1998:48:369-73.

28 Wu TN, Shen CY, Lai JS, et al. Effects of lead and noise exposures on hearing ability. Arch Environ Health 2000;55:109-1 14.

29 Bener A, Obineche E, Gillett M, et al. Association between blood levels of lead, blood pressure and risk of diabetes and heart disease in workers. Int Arch Occup Environ Health 2001 ;74:375-8.

30 Sroczynski J, Zajusz K, Kossmann S, et al. Effect of experimental lead poisoning on the development of arteriosclerosis. Pol Arch Med Wewn 1967;38:641-6.

31 Sroczynski J, Zajusz K, Kossmann S, et al. The effect of experimental lead poisoning on the development of atherosclerosis. Pol Med J 1968:7:196-201.

32 Revis NW, Major TC, Horton CY. The effects of calcium, magnesium, lead, or cadmium on lipoprotein metabolism and atherosclerosis in the pigeon. J Environ Pathol Toxicol 1980;4:293-304.

33 Tarugi $\mathrm{O}$, Calandra S, Borella $\mathrm{P}$, et al. Heavy metals and experimental atherosclerosis. Atherosclerosis 1982:45:221-34.

If you can't find what you are looking for in Occupational and Environmental Medicine you can extend your search across many of the more than 200 journals available for selection. You can restrict your search to specific subject areas (eg, clinical medicine, basic research), or select specific journals, or search all available titles.

\section{www.occenvmed.com}

